\title{
Research on Legal Prevention System of Food Safety Risk in China
}

\author{
Ya-Ru LIU \\ School of Political Science and Public Administration, University of Electronic Science and \\ Technology of China, Sichuan Chengdu 611731 \\ yaruliuweihan@163.com
}

Keywords: Food Safety Risk, Legal Prevention System, Social Co-Governance.

\begin{abstract}
China's food safety risk legal prevention system has restricted adjustment objects, chaotic risk information security system, complicated food safety standards and food safety supervision disconnection and other deficiencies. Based on the situation of China, the transformation from single regulation to "social co-governance" should be made by establishing the whole-process supervision system and standard legal system, combined with successful foreign experience, to provide choices for optimizing China's legal prevention system of food safety risk.
\end{abstract}

\section{Introduction}

The Food Safety Law of the People's Republic of China (Hereinafter referred to as Food Safety Law) revised in 2015 puts forward the concept of "social co-governance", and establishes the legal mechanism of food safety risk prevention and control, which improves the risk monitoring and evaluation system further. Food safety risk prevention legal mechanism under the concept of social co-governance mobilizes all the forces of society to cooperate with the government to participate in the food safety risk prevention and control under the guidance of the government. China is currently at the transition period of food safety system reform, when the food safety field has begun to reflect the "high risk" characteristics. Different stakeholders are kept in a same food value chain. The difference of value appeal decides that the operators, the government and consumers can not form common values ideas and norms of behavior spontaneously. The guarantee of food on human survival is obstructed by the law of value under market economy. Therefore, the research on the legal prevention system of food safety risk for the initiative release of risks in a controllable way will be of great significance to the increase of the legal prevention system of food safety risks in China.

\section{The Current Status of the Legal Prevention System of Chinese Food Safety Risks}

China has not yet realized systematic legal prevention and control of food safety risks, which have wide sources, including problems in food production and processing, circulation and consumption and other link, which are difficult to control. China's legal prevention of food has changed from the "food hygiene" to "food safety", with the basic law of Food Safety Law formed, as well as food market access, product labeling and nutrition labeling, circulation security guarantee, security information dissemination and other local laws and regulations, departmental rules and local regulations, with the initial formation of the central and local, comprehensive and professional food safety risk prevention legal system.

\section{The Main Body of Prevention and Control}

The government plays a leading role in China's food safety risk prevention and control. Before the super-ministry system reform, the supervision model of "multi-sectoral segmented supervision domination, supplemented by the variety supervision" has problems of omission, leakage and responsibility overlap in the food problem supervision. The problems remain unsettled after the "three-in-one" reform. In addition, the grass-root market regulators have been established, but the higher authorities are still food and drug regulation, industry and commerce, quality supervision and other departments. The overlapping functions between the upper and lower levels, the non-separated 
risk management and assessment easily lead to mutually making excuses, low administrative efficiency and the waste of resources, making the corresponding functions unable to be fulfilled normally, and risk prevention can not be carried out effectively. Food has life cycle, and its behaviors of production and management should be continuous, any artificial segmented supervision may lead to mistakes, thus affecting its safety ${ }^{[2]}$.

The Food Industry Association makes risk prevention and control as a body at the middle layer of the society. Article 3 of the new Food Safety Law embodies the food safety risk prevention and control, and puts forward social co-governance concept. To promote co-governance by "reachingconsensus", through the cooperation of food industry association, the power of the public and all circles of society, it realizes the goal of social co-governance.

\section{The Transformation of the Concept}

Food safety risk prevention and control covers all aspects of food supply chain including primary production, food production, processing, circulation and marketing. From the official implementation of Food Hygiene Law of the People's Republic of China in 1995 to the revised Food Safety Law in 2015, the concept of food safety risk prevention and control has changed from food quality safety to the prevention and control, and the means and methods of prevention and control have always been increasing. During the period, China promulgated the Provisional Regulations on the Administration of Food Hygiene, since when the food safety risk prevention and control scope began to increase, and the prevention and control concept changed from passive control to active prevention.

At present, China's food safety risk prevention and control means show a diversified trend, and standard market access system, in the meanwhile, the supervision on the circulation is enhanced. The traditional decentralized management system is changed into the unified supervision and management system, and the supervision is made both the enterprises and products from the product supervision only, and the terminal control is the whole-process supervision of food supply chain, and the risk prevention and control is made actively.

\section{The Status Quo of Legislation}

First, the new Food Safety Law explicitly builds a risk monitoring and risk assessment system. It stipulates on the food safety risk monitoring system in details, including that the administrative department in charge of food hygiene should make full use of the make full use of subjective initiative implement the monitoring plan, and the risk prevention. Second, the new law specifies the national food safety standards. Article 28 of the National Food Safety Standard stipulates on the national standards the audit subject and production and processing abide by, including the experts of food related areas into the audit subject and its composition members, to audit the scientificity and rationality of the examination standard and dictates the basis for the development of national standards. Finally, the new law legislate and standardize the food safety and quality market access system, recall system and licensing system, which enhances the ability of food safety risk prevention and control.

\section{The Dilemma of China's Food Safety Risk Legal Prevention System in Practice}

China's food safety risk law prevention and control system has gaps and omissions on the institutional system and prevention and control contents. Specifically speaking, the current risk prevention and control system has narrow adjustment range and incomplete risk information system. On the prevention and control system, the overall structure is more dispersed, the cooperative degree between the constructive elements of the system is low, and the risk information security system is chaotic. Details are as follows:

\section{The Narrow Adjustment Objects of Risk Prevention System}

"A successful legislative process requires the results of legislation to benefit different stakeholders in different ways" [3], the prevention and control institutional system should give the operators, 
regulators and consumers corresponding status as legal subjects. China's Food Safety Law stipulates on the prevention and control status of different subjects, and establish a supervision mechanism with the government regulation dominating, supplemented by the coordinated supervising and management of multiple departments. Food production operators bear the obligation of business regulation, complies with the hygiene and food safety control standards to ensure food safety. Consumers enjoy the right to know the food safety information and report the illegal activities. However, due to the deeply-rooted public power, the central legal status of the public in the prevention and control is affected, resulting in narrow adjustment objects.

\section{Low Cooperative Degree Between The Constructive Elements of The Prevention And Control System}

First of all, the coordination degree between public's social supervision power and government regulatory power is not high. At present, the public participation in the communication process of food safety risk is low, but the government regulation didn't transformed into social co-governance mode [4]. Second, the unscientific authority allocation pattern and lack of capacity-building cause low internal cooperation of regulatory power. In addition, the coordination channel between the regulatory power and operator's obligation of prevention and control is not smooth. The Food Safety Law clarifies the scope of business conduct with prohibitive provisions, and stipulates on the risk examination and assessment goals, institutions, procedures and food recall systems, safety standards updates, safety incident handling, food ingredients, information dissemination and other systems. But in practice, the regulatory power is highly dependent on the main body status of the operators, and the focus of supervision is subject admittance and market behaviors. The information trace-aback system is weak and lacks the information feedback from the public.

\section{The Chaotic Security System of Risk Information}

On the one hand, the current boundary of release and privacy of food safety risk information is blurred, and the food safety information itself also has certain injurious effect [5]. Article 82 of the Food Safety Law, Article 4 of the Regulations on the Implementation of the Food Safety Law and the Management Method of Food Safety Information promulgated by the Sixth Ministry of the Ministry of Health have insufficient legal protection of the information content and transmission in the course of supervision. The transmission mechanism of information between government regulators can not meet the objective needs of prevention and control. The integration and distribution of risk information concentrate on the health sector, but the source, screening and management behaviors of information are carried by other departments; the government risk information contents are uniform formally, and the prevention foundation and the relation between prevention and control is not clear substantially. The obligation and responsibility of the main body of risk information are confused. On the other hand, the scope, procedures and transparency of risk information are one-way. Although China's legislation has a series of provisions on the release of risk information, most of which are functional provisions. The public information scope and content are decided by the regulatory authorities unilaterally, with the lack of legal feedback procedures on the public information appeal. The obligation of operators and regulators on risk information disclosure lacks interaction. In general, the transparency of information security mechanism is low.

\section{Factors Resisting the Implementation of the Food Safety Risk Legal Prevention System in China.}

At present, China lacks the food safety risk legal prevention systems and the food safety standard systems are not sound. The segmented supervision has disconnected supervision within the links and between different links. In addition, the food safety risk prevention and control system lacks complete assessment mechanism and consumer participation. There are many difficulties during the implementation, such as: 


\section{The Unsound Food Safety Legal System}

China's current food safety legal system is mainly developed under the reform of government institutions, with special legislative environment and the legislative mode, so the rules and regulations on food safety are inconsistent. On the one hand, China's food safety legal system is not perfect, mainly by the food production safety and quality standards and related laws, wide content, legislative blank and target dislocation obvious, resulting in law enforcement can not follow the phenomenon. On the other hand, China's food safety legal system lacks unity, with scattered provisions, without according with the international code.

\section{Chaotic and Complicated Food Safety Standard System}

China has food safety product standard, food additives standard, food packaging standard and food processing machinery standards at present, as well as national standards and industrial overlapping and contradictory standards. Some key food standards legislation are blank with the lack of complete sets of standard involved in food production, processing and circulation. The entire food standard system is complex, seemingly to be detailed, but lacks specific food safety standards, which makes it more difficult to carry out food safety risk prevention and control in China.

There are also some problems in the standard setting. The initiation of standards in China is supported by the government and bidding company on halves, namely a half of the money is from the enterprise. So the formulation of standards is generally affected by the enterprise. Ultimately, the standard is subject to the enterprise and management department only.

\section{Gappy Segmented Supervision Food Safety}

Segmented supervision of food safety has resulted in repeated regulation and regulatory blindness. With the development and expansion of the food industry, food supply chain is also becoming more complex. The staged supervision is not so easy to control as before, which can not fully cover the increasingly diversified food industry, in the meanwhile, the supervision departments are unaware of the things they are in charge of, thus resulting in a gray zone. The main reason for the repeated supervision is that there are too many main bodies, each of which wants to benefit from the lucrative matters, but tends to neglect non-lucrative matters.

Fourth, Research on the Implementation Path of Legal Prevention and Control System of Food Safety Risk in China

The author believes that the improvement of China's food safety risk prevention and control mainly includes the following four aspects:

\section{Completing the Transition From Single Supervision to "Social Co-Governance"}

Food safety issues is a major social problem. Food safety has a wide range of stakeholders, so a community with a common future should be established. In the food safety risk prevention and control, in order to improve efficiency, the risk assessment agencies, risk exchange agencies, risk management agencies, the public, the media and other stakeholders should perform their own functions respectively. A single government-dominant governance model has been unable to cope with the current frequent food safety events [6]. In the food safety risk prevention and control, the food safety risk assessment center lacks independence as the main body and the value standpoints of the administrative organizations may have deviations, but the experts may not be reasonable, and the public's value demands can not be responded positively[7]. The co-governance effect of the media should be made full use of, in addition, experience should be learned from the developed countries. Excellent food safety experts should be selected to build a full time food safety committee, to specialize in food safety work. In addition to be qualified for the technical work, they should also attach great importance to the public interests from the emotional level and communicate with the public systematically[8], to enhance trust and achieve social co-governance. 


\section{The Establishment of Whole-Process Supervision System of Food Safety Risk Prevention and Control}

The whole-process management of food safety risk prevention and control should be conducted from pre-prevention, management and post-processing. It is the government that should be the first to make pre-prevention, which should play its subjective initiative, and analyze and control the matters as soon as possible. After the food crisis breaks out, the government should take measures timely to win the favor of the public. It should strengthen food safety liability insurance supervision, stabilize the market situation of food liability insurance, give guidance while supervising. As to the food safety risk prevention and control, in order to reduce the damage of food safety risks, the consumers should be informed of the facts in time. Besides government prevention and control, the consumers should make prevention and control on their own, to build a platform for the release of food safety information, standardize the information released by the media and measure the monitoring and release of the public feelings. After the food safety incidents occur, the government should give response to the recall system actively, and locate the food and take preventive measures.

\section{The Development of Legal System On The Food Safety Risk Prevention and Control Standard}

In the food safety risk prevention and control legal system, the standard is particularly important. China can learn from developed countries for the development of food safety risk prevention and control standards. It should clarify the main body of the standard, establish comprehensive participating system, and strive to realize " social co-governance", and take into account the interest appeal of each main body, to reach the maximum common divisor of social benefits. At the same time, it should improve modification procedure of the food safety risk prevention and control standards, reinforce scientific assessment of the food safety risk prevention and control, establish system database, and provide parameters for risk assessments, thereby developing scientific food standards effectively, and control the food risk conditions accurately.

\section{Strengthen the International Exchange and Cooperation of Food Safety Risk Prevention and Control}

With the global development, the food safety prevention and control has been back on track in developed countries and regions, and the food industry has become a business system of global production and distribution. China is a big country of food trade, whose ignorance of the international cooperation of prevention and control system in food safety legislation must be changed. Although China has joined the Network for International Food Risk Exchange Center Cooperation in 2012 [9], there are still problems, such as inadequate exchange with international companies in the same industry on the food safety matters at the early stage and food safety risk prevention and control and so on. On the one hand, we can carry out all-round, multi-level prevention and control system to build international cooperation. On the other hand, we can promote international cooperation in the construction of prevention and control system. Strengthen the reach on the international treaty law, customary law and other "soft law" document of Food Safety Committee, and quicken the transformation of international law resources into domestic resources, promote the consistency between the risk assessment and risk management methods, enhance international culture communication, intensify the grasp and release of foreign rules and regulations on food safety, and strive to be consistent with the international trend of food safety risk prevention and control.

\section{References}

[1]Si Chen, Aidong Liu, Xi Lu, Kai Zhong, etc. The Risk Perception of Food Additives of Chinese Rural Residents and Influencing Factors [J]. Chinese Journal of Food Hygiene, 2016, 1: 115-118.

[2]Fang Zhang. The Development and Improvement of Chinese Modern Food Safety Supervision Legal System [J]. Political Science and Law, 2007 (5): 78 - 80. 
[3]Michael R. Taylor. Lead or React? A Game Plan for Modernizing the Food and Drug Law Journal[J], 2004(59): 403.

[4]Ganghong Deng. Construction of the Legal Logics and Path of Food Safety Social Co-governance Mode [J]. Social Sciences in Nanjing, 2015 (2): 97 - 102.

[5]Lixia Pan, Xingui Xu. On the Publicity of Government Information in Food Safety Supervision [J]. Chinese Public Administration, 2013 (4): 29 - 31.

[6]Linhai Wu,u Xin Lvy, Lijie Shan,etc. Study on the Behavior of Village Committee Participating in Rural Food Safety Risk Management Based on Realistic Situation [J]. China Population, Resources and Environment, 2016, 9 (26): 82 - 91.

[7]Jiangang Qi, Jingyue Zhang. On the Crisis of Confidence of Chinese Legal System on Public Risks Supervision - From the Perspective of the Theory of Process [J]. Social Sciences in Yunan 2015(4):122-127.

[8]Guo Qianqian, Hideki Harasawa. Fruit Processing Product Quality and Food Safety Risk Detection Scheme Based on HACCP System [J]. Journal of Applied Science and Engineering Innovation, 2016, 1 (3) : 13- 17.

[9]Qunan Mao. Introduction to Food Safety Risk Exchange [M]. Beijing: People's Medical Publishing House, 2014: 30. 